\title{
Investigation of Cell-Matrix Interactions Using a FRET Technique
}

\author{
Munira B. Shahbuddin, Honghyun Park, Jae Won Lee, Soyeon Park, and Kuen Yong Lee ${ }^{-}$ \\ Department of Bioengineering, Hanvang University; Seoul 133-791, Korea. ${ }^{\circ}$ E-mail: leehwähanvang.ackr \\ Received Jine 30, 2009, Accepted July 03, 2009 \\ Controlling cell-matrix interactions is critical in regulating cell phenotypes for tissue engineering applications. \\ Cellular adhesion to synthetic extracellular matrices (ECMs) can be enhanced by introduction of adhesion ligands \\ to the matrices. We tested the hypothesis that biophy sical cues such as ligand organization in synthetic ECMs play \\ an important role in modulating cell responses to the microenvironment. To investigate and monitor cell-matrix \\ interactions, we used a fluorescence resonance energy transfer $(\mathrm{FRET})$ technique with cell-interactive polymers \\ generated by conjugating a peptide with the sequence of arginine-glycine-aspartic acid (RGD) to alginate hydrogels
}

Key Wonds: RGD peptide, Alginate hydrogel. Ligand organization. FRET, Tissue engineering

\section{Introduction}

Tissue engineering aims to replace. maintain and/or improve tissue functions in the body using an interdisciplinary approach that requires the principles and methods of engineering and life science. In tissue engineering, it is essential to use polymeric scaffolds to mimic the function of the extracellular matrix (ECM) and create microenvironments suitable for cell and tissue growth. Controlling cell-matrix interactions such as biocompatibility. biodegradability. mechanical integrity and cell attachment via chemical or plysical modification of matrices is critical to regulate the gene expression of the cells to be engineered. ${ }^{2}$

Controlling cellular adhesion to a matrix is essential in tissue engineering approaches. as both cell fate and phenotype can be regulated by cellular adhesion. ${ }^{3.4}$ Integrin receptors of cells play important roles in cellular binding to a matrix and this can be biophysically regulated by physical arrangement of adhesion ligands as well as by matrix rigidity. "Cellular interactions can be improved by introduction of a peptide with the sequence of arginine-gly cine-aspartic acid (RGD) to a matrix. "This peptide sequence has been widely investigated and used as a cell adhesion ligand that specifically binds to integrin receptors of cells. including $\alpha_{4} \beta_{3}$ and $\alpha_{5} \beta_{1}$. It has been frequently reported that the bulk density of RGD peptides in polymer matrices can regulates the proliferation and/or differentiation of various cell types in vitro and in wivo, ${ }^{8,9}$ In addition, spacing between adhesion ligands on the tens of nanometers scale has been found to be important in regulation of spreading, growth, and differentiation of preosteoblasts in vitro. ${ }^{\text {"1 }}$

We hy'pothesize that controlling the distance between RGD islands influences the cell adhesion strength of fibroblasts. which can affect cellular growth on the ligand-organized polymer matrices. We used hydrogels as a matrix for cell culture, as hydrogels are structurally similar to macromolecular-based materials in the body. Alginate. a natural polysaccharide extracted from seaweed, has been used to form hydrogels due to its biocompatibility and low toxicity. as well as wide applications in miny biomedical areas. "In this study, a fluorescence resonance energy transfer (FRET) technique was used to investigate the effect of ligand organization on cell-matrix interactions as well as relationship with cellular adhesion and growth. This FRET technique has been widely used in studies of biological interactions including proteins and cells. ${ }^{12-15}$ as this approach does not require mechanical/chenucal perturbation or cell stimulation, which may potentially alter cellular traction and adhesion forces. ${ }^{16}$

\section{Experimental}

Synthesis of RGD-modified alginate. Peptide-modified alginate was prepared by standard carbodiimide chemistry using ultrapure MVG alginate (MW $=200.000-300,000$, FMC Biopolymers) and Gly 4 -Arg-Gly-Asp-Ala-Ser-Ser-Lys (G $\mathrm{G}_{4}$ RGDASSK: Any gen). Sodium alginate was dissolved in 2 -( $N$-morpholino) ethanesulfonic acid (Sigma) buffer ( $\mathrm{pH} 6.5,0.3 \mathrm{M} \mathrm{NaCl}$ ) at room teniperature overnight. Peptide was added to the alginate solution in the presence of $\mathrm{N}$-hy'droxy'sulfosuccinimide (sulfoNHS: Pierce) and l-ethyl-3-(dimethy laminopropyl) carbodiimide (EDC: Aldrich). The peptide-modified alginate was purified by extensive dialysis against deionized water for four days (molecular weight cut-off, 3500). activated charcoal treatment. and sterilization through $0.22-\mu \mathrm{m}$ filter. The degree of substitution (DS) was defined as the total number of RGD peptides per alginate chain and was altered by varying the concentration of RGD peptides. ${ }^{16}$

Fuorescence labeling. Peptide-modified alginate was labeled with Alexa Fluor 488 (Invitrogen). The molar ratio between Alexa Fluor 488 and peptide was kept constant at $1: 1$. In this reaction. fluorescence molecules were added to an alginate solution dissolved in MES buffer at $\mathrm{pH} 6.5$. Both fluorescencelabeled RGD-alginate and fluorescence-labeled non-peptidemodified alginate were synthesized. purified by dialy'sis and active charcoal treatment, sterilized through a $0.22-\mu \mathrm{m}$ filter, and freeze-dried for four day's. Dried alginate samples were constituted with Dulbecco's Modified Eagle Medium (DMEM: Gibco, no phenol red) at a concentration of $2 \mathrm{wt} \%$.

Preparation of RGD-modified alginate hydiogels. Hydrogel disks were prepared by ionic cross-linking of an alginate solution ( $2 \mathrm{wt} \%$ ) with calcium sulfate ( $20 \%$ ) using sy ringes connected with a female connector. The mixture was poured onto a glass 
plate (separated by $1.0 \mathrm{~mm}$ thick spacer). and then covered by another glass plate for $20 \mathrm{~min}$. The gels were cut into $1 \mathrm{~cm}$ diameter using a punch and swollen in DMEM overnight. Ligand-organized hydrogels were prepared using a simple mixing of RGD peptide-modified alginate with non-peptide modified alginate. All hydrogels used in this study had the same bulk RGD concentration. but differed in the distance between RGD islands (i.e.. RGD clusters). The distance between RGD islands was calculated using the specific volume of a single alginate chain in the gel under the assumption of an even distribution of peptides in the gel. ${ }^{\text {l( }}$

Cell culture and staining. $\mathrm{NH} 3 \mathrm{~T} 3$ mouse fibroblasts were purchased from Korea Cell Line Bank, cultured and expanded in DMEM containing $10 \%$ FBS and $1 \%$ penicillin-streptomycin (PS). Cells were then try psinized with try psin-EDTA solution and centrifuged for removal from the cell suspension. Cell membranes were stained with octadecyl rhodamine B chloride (Invitrogen) for $2 \mathrm{~h}$ at $37^{\circ} \mathrm{C}$ under $5 \% \mathrm{CO}$ atmosphere. Excess rhodamine molecules were removed. and the stained cells were re-suspended in fresh DMEM without phenol red. Cells were seeded onto alginate gel disks with different RGD island spacing and incubated at $37^{\circ} \mathrm{C}$ in the presence of $5 \% \mathrm{CO}_{2}$ atmosphere.

Immunostaining of vinculin. A cell suspension in DMEM $\left(5 \times 10^{4}\right.$ cells $\left./ \mathrm{mL}\right)$ was seeded onto ligand-organized alginate gel disks and incubated at $37^{\circ} \mathrm{C}$ under $5 \% \mathrm{CO}_{2}$ atmosphere for $10 \mathrm{~h}$. Non-adherent cells were removed by washing with PBS and adherent cells were fixed with $10 \%$ formalin solution containing sucrose and cytoskeleton buffer. Cells were then treated with $\mathrm{AbDil}$ for $10 \mathrm{~min}$, followed by treatment with anti-human vinculin antibody (primal antibody, 1:200 dilution. Chemicon) for $5 \mathrm{~min}$. The cells were then treated with rhodamineconjugated donkey anti-mouse IgG (secondary antibody) (Jackson ImmunoLab). The gel disks were rinsed with TBS buffer containing $0.1 \%$ Triton $\mathrm{X}$ for five times and mounted on a cover slip before sealing with wax. Images of vinculin-stained cells were takenby confocal laser scanning nicroscopy (Olynpus).

Fluorescence measurement. Fluorescence emission was measured with a spectrophotometer (Molecular Devices). Hydrogels with different island spacings of fluorescein-labeled RGD peptides were put into a 24 -well tissue culture plate and preswollen in DMEM without phenol red overnight $\left(37^{\circ} \mathrm{C}, 5 \%\right.$ $\mathrm{CO}_{2}$ atmosphere). Octadecyl rhodamine B-labeled cells were then seeded onto each gel and incubated for $6 \mathrm{~h}$. After removing the media, fluorescence emission spectra were recorded $\left(\lambda_{\mathrm{ex}}=\right.$ $494 \mathrm{~nm}$ ). The degree of energy transfer $(\psi)$ was determined from the emission intensity of the donor (fluorescein) in the absence $\left(\mathrm{I}_{\mathrm{D}-\mathrm{A}}\right)$ and presence $\left(\mathrm{I}_{\mathrm{D}+\mathrm{A}}\right)$ of the acceptor (rhodamine) using the following relationship: ${ }^{1}$

$$
\psi=1-\frac{I_{D+A}}{I_{D}-A}
$$

Rheological measurement. The viscoelastic properties of ligand-organized hýdrogels were measured by a rotational rheometer (Malvern Instrument) using a fixture of parallel plates. The gap opening was set to $800 \mu \mathrm{m}$ and the stress amplitude was fixed at $0.1 \mathrm{~Pa}$. The samples were completely covered with a solvent trap to prevent the evaporation of water during the measurement. The temperature was kept constant at $37.0 \pm 0.1^{\circ} \mathrm{C}$.

Cell adhesion assay. Briefly. NIH3T3 cells were seeded onto ligand-organized alginate gels $\left(5 \times 10^{5}\right.$ cells $\left./ \mathrm{mL}\right)$ and incubated for 12 h at $37^{\circ} \mathrm{C}$ under $5 \% \mathrm{CO}_{2}$ atmosphere. Each gel disk was turned upside down and transferred to a porous cell strainer ( $100 \mu \mathrm{m}$. pore size). The cell strainer containing the gel disk was placed into a $50-1 \mathrm{~mL}$ conical tube filled with media and the conical tube was then centrifuged with $50 \mathrm{~g}$ centrifugal force for 10 min. To collect adhered cells after centrifugation. the gel disk was transferred to another conical tube containing 50 mM EDTA and $0.05 \%$ trypsin solution and incubated for 10 min at room temperature. After the gel was completely dissolved. cells were collected and the number of cells was counted by a Coulter counter (Beckntan). The fraction of cells adherent after centrifugation nonmalized to the total number of cells adhered. was calculated and used as a measure of cell adhesiveness to the gels.

\section{Results and Discussion}

Characteristics of ligand-modified alginate hydlogels. Cellinteractive polymers were synthesized by chemical conjugation of RGD peptides to an alginate backbone. Hydrogels with various $\mathrm{RGD}$ island spacings were prepared to test whether the phenoty pe of adhered fibroblasts could be regulated by the spatial organization of adhesion ligands on a nanometer scale (Fig. 1). The bulk RGD density was kept constant. while the island spacing (i.e.. distance between RGD peptide clusters) varied from 36 to $78 \mathrm{~nm}$. Fibroblasts were seeded on the surface of gels with an average island spacing of 36,50 and $78 \mathrm{~mm}$. while a constant bulk RGD density of $16.7 \mu \mathrm{g} / \mathrm{mg}$ alginate was maintained. The various characteristics of ligand-organized alginate hydrogels with different RGD island spacings are listed in Table $\mathrm{l}$. The water content and mechanical properties of all alginate hydrogels used in this study were not significantly affected by ligand organization.

Cell adhesion and spereading on ligand-organized hydrogels. We investigated the effects of ligand organization on the adhesion and spreading of fibroblasts. and determined the aspect ratios and growth rates of the cells cultured on the gels with different RGD island spacings. Although the initial number of cells attached to the hydrogels was sinular, the growth rates were significantly different after three days of culture. depending on the RGD island spacing. The growth rates of fibroblasts increased as the distances between RGD islands decreased (Table 2). The

- Ligand

II Receptor

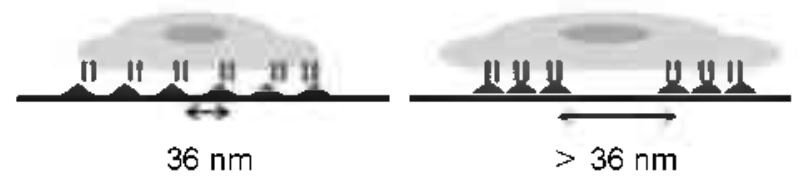

Figure 1. Schematic description for controlling specific receptorligand interactions between cell (e.g., fibroblast) and matrix (e.g., alginate hydrogel i by ligand organization. 
Table 1. Characteristics of RGD peptide-organized algunate hydrogels

\begin{tabular}{cccccc}
\hline $\begin{array}{c}\text { RGD island spacing } \\
(\mathbf{n m})\end{array}$ & $\begin{array}{c}{[\mathrm{RGD}]} \\
\text { (!lg/mg alginate) }\end{array}$ & Dilution factor & $\begin{array}{c}\text { Number of peptide } \\
\text { per alginate chain }\end{array}$ & $\begin{array}{c}\text { Elastic modulus (G') } \\
\text { (at } 1.0 \mathrm{~Hz})\end{array}$ & $\begin{array}{c}\text { Water content } \\
(\%)\end{array}$ \\
\hline 36 & 16.7 & 1 & 2 & $103.4 \pm 14.7$ & 95.3 \\
50 & 16.7 & 2 & 4 & $101.9 \pm 16.4$ & 95.2 \\
78 & 16.7 & 10 & 20 & $108.1 \pm 14.6$ & 95.3 \\
\hline
\end{tabular}

Table 2. Cellular responses to RGD peptide-organized alginate hydrogels

\begin{tabular}{cccc}
\hline $\begin{array}{c}\text { RGD island } \\
\text { spacing (nn) }\end{array}$ & $\begin{array}{c}{[\mathrm{RGD}]} \\
(\mu \mathrm{g} / \mathrm{mg} \text { alginate })\end{array}$ & Aspect ratio & $\begin{array}{c}\text { Growth rate } \\
\left(\text { day }^{-1}\right)\end{array}$ \\
\hline 36 & 16.7 & $4.0 \pm 0.5$ & $1.7 \pm 0.05$ \\
50 & 16.7 & $5.5 \pm 1.0$ & $1.4 \pm 0.02$ \\
78 & 16.7 & $8.1 \pm 0.6$ & $1.2 \pm 0.02$ \\
\hline
\end{tabular}

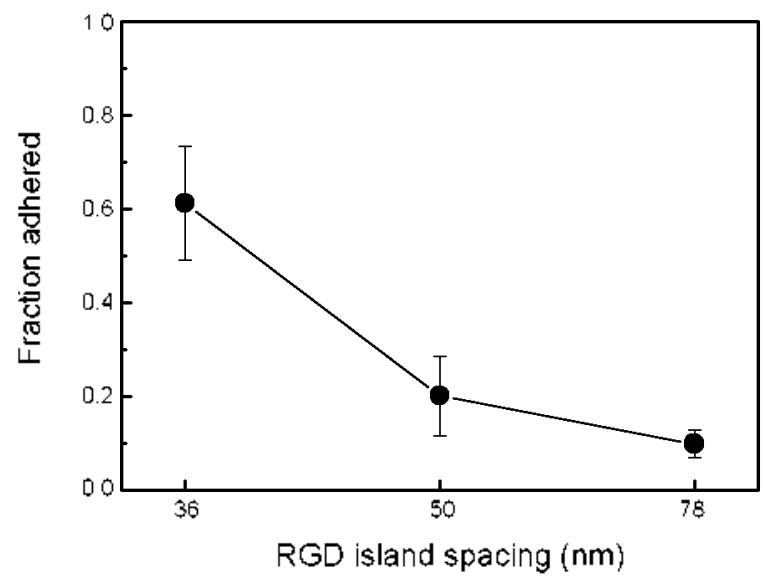

Figure 2. Relationship between cellular adhesion strength and RGD island spacing in a gel.

NIH3T3 cells that adhered to gels with an RGD island spacing of $78 \mathrm{~nm}$ displayed a more extended morphology than those that adhered to gels with an RGD island spacing of $36 \mathrm{~nm}$. Cellmatrix adhesion strength was analyzed by determining the fraction of adherent cells after centrifugation with a defined force. The fraction of adherent fibroblasts on gels with an RGD island spacing of $36 \mathrm{~nm}$ was higher than for other groups (Fig. 2), indicating a stronger adhesion force for cells on ligand-organized gels with shorter RGD island spacings.

Measurement of cell-matrix interactions using FRET. We next investigated cell-matrix interactions using a FRET technique. When FRET occurs. emission energy from an excited donor molecule transfers to an acceptor molecule and the fluorescence intensity of the donor molecule decreases. ${ }^{16}$ This energy transfer depends on the distance between two fluorescent molecules. When two molecules are closely located to each other (e.g. within a few nanometers) energy transfer occurs. In this study, we found that the degree of energy transfer $(\psi)$ was strongly dependent upon the distance between RGD islands in the gels. The degree of energy transfer between cell and matrix with an island spacing of $36 \mathrm{~nm}$ was higher than that for other island spacings (Fig. 3), indicating more prominent cell-matrix interactions for cells on ligand-modified gels with shorter

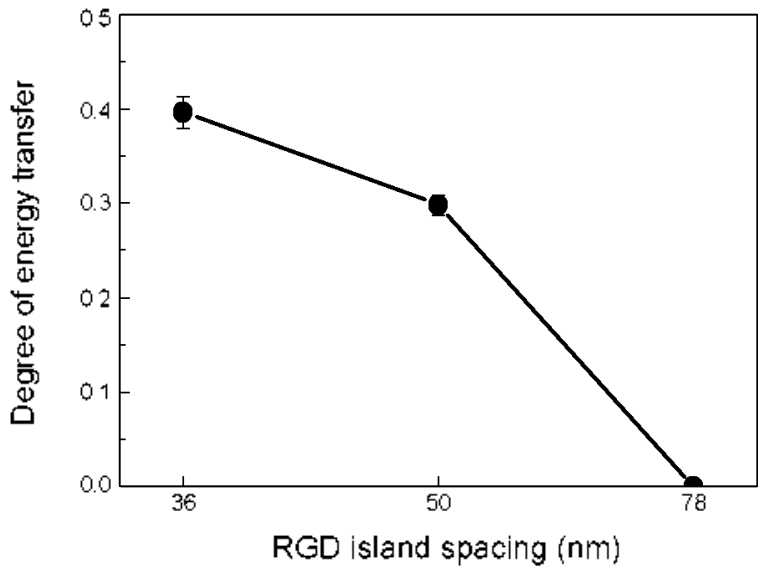

Figure 3. Changes in the degree of energy transfer $(\psi)$ for fibroblasts adhered to alginate gels with different RGD spacing.

ligand island spacings. This finding was consistent with RGD island spacing-dependent results for morphology and growth rate of fibroblasts.

Focal contact fomation. We further investigated cell-matrix interactions in terms of focal contact formation on the ligandorganized gels. as cell adhesion and spreading were dependent on the RGD island spacing. Visualization of vinculin provided direct evidence that the focal adhesion of fibroblasts depended on the RGD island spacing. Focal adhesion was observed for fibroblasts cultured on gels with the short RGD island spacing (Fig. 4). The cell spreading was more evident for gels with the greater island distance with traction at the leading edge area. The decrease in the growth rate with an increase in RGD island spacing is shown in Table 2 and this could be explained by the lack of focal adhesion formation on ligand-organized lydrogels and the decrease of cell's contractility with the substrates. ${ }^{18}$

We found that the distance between RGD islands is essential for the formation of integrin-mediated adhesion. and this finding was consistent with the changes in the growth rate and adhesion of cells adhered on ligand-organized gels. Closely spaced ligands promote Rho-family GTPases that induce cell spreading and motility: while wider spaced ligands support cell differentiation ${ }^{19}$ Focal adhesion inplies that cells can sense the elasticity of the matrix and respond to it by distinguishing between soft and rigid matrices. In our system. organization of adhesion ligands did not alter the mechanical cues (Table l). Therefore, biophy sical cues in the matrix influenced cell morphology and adhesion strength based on the distance between RGD islands. Although the molecular nature and mechanism of action in this sy stem is not fully known yet, our experiments provide initial quantification of the response by measuring the degree of cell-matrix interaction using a FRET technique and cellular adhesiveness 

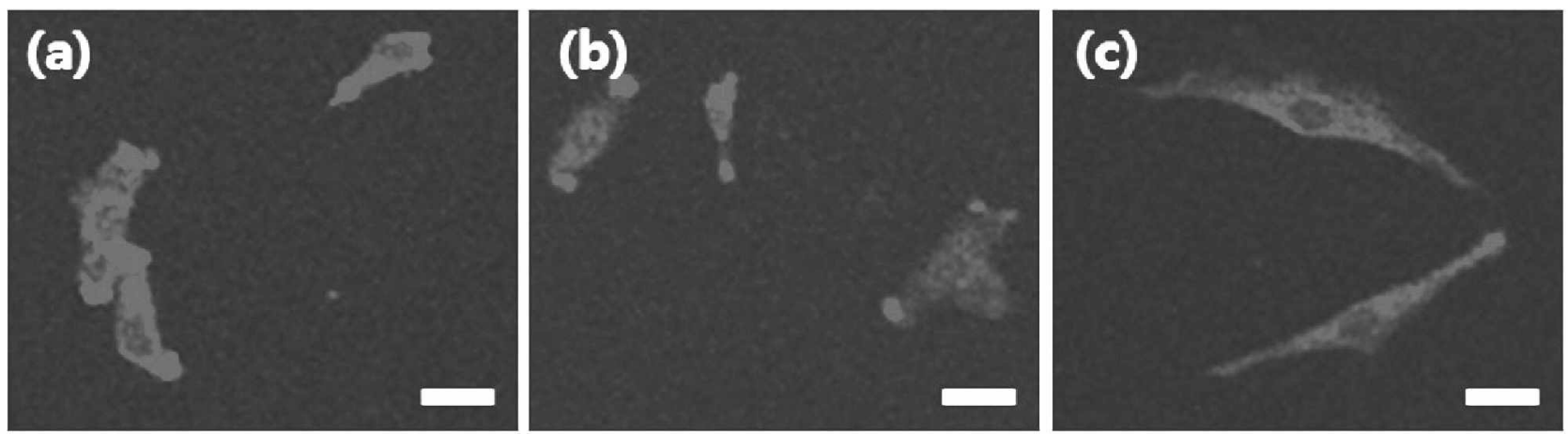

Figure 4. Confocal microscopic images of mmunostained vinculin of fibroblasts cultured on alginate gels with RGD island spacing of (a) 36 , (b) 50 , and (c) $78 \mathrm{~cm}$, respectively.

assay. The ne.t challenge would be to explore the structure and function of cell-matrix interactions in a three-dimensional microenviromment in vivo.

\section{Conclusion}

Ligand organization in a gel on the nanoscale range significantly influences cellular adhesion, spreading, and growth. We used a FRET techuique to analyze cell adhesiveness in order to elucidate cell-matrix interactions. RGD islands in a gel matrix that were spaced on a ninometer scale revealed the highest growth rate and adhesion strength for cells cultured on the gel. in comparison to matrices with longer RGD island spacings. Understanding the complexity of cell-matrix interactions can be a useful tool for effective biomaterial design in tissue engineering applications.

Acknowledgments. This work was supported by the research fund of Hanyang University (HY-2006-I).

\section{References}

1. Langer, R.: Vacanti I. P. Science 1993, 260,920.

2. Drury, J. L.; Mooney, D. T. Biomaterials 2003, 24, 4337.

3. Comisar. W. A.: Kazmers. N. H.: Moonev, D. J.: Lindennann. I. I. Biomaterials 2007, 28, 4409 .
4. Gumbiner, B. M.; Yamada K. M. Cmrent Opinion Cell Biol. $1995,7,615$

5. Peyton, S. R.; Kim, P. D.; Ghajar, C. M.; Seliktar, D; Putnam, A. J. Biomaterials 2008, 29.2597.

6. Rowley, J. A.; Madlambayan, G.; Mooney, D. T. Biomaterials $1999,20,45$

7. Genes, N. G.: Rowley, J. A.; Mooney, D. J.: Bonassar, L. I. Arch. Biochent. Biophys. 2004, 122,161 .

8. Schense, J. C.: Hubbell, T. A.J. Biol. Chem, 2000, $275,6813$.

9. Alsberg, E.: Anderson, K. W: Albeiruti, A.: Rowley, T. A.; Mooney, D. J. Proc. Natl. Acad. Sci. LS. 2002, 99, 12025.

10. Lee, K. Y.; Alsberg, E.: Hsiong, S.; Comisar, W.: Linderman, T.; Ziff, R: Mooney, D. Nano Letters 2004, 4, 1501

11. Lee, K. Y: Mooney, D. J. Chent Rev. 2001, 101, 1869.

12. Park, H.: Lee, M.; Seong, G. H.; Choo, I.; Lee, E. K.: Park, I. Y.; Lee, S.; Lee, K.-H.; Choi, Y.W. Bull. Korean Chem. Soc. 2008, 29, 1297.

13. Kikuchi, K.; l'akakusa, H.: Nagano, 1. Trend thal Chem. 2004 , 23,407

14. Sekar, R. B.: Periasamy, A. J. Cell Biol. 2003, 160,629.

15. Medintz, I. L. Trend Biotechol. 2006, 24, 539 .

16. Kong, H. J.; Polte, I. R.; Alsberg, E.; Mooney, D. T. Proc. Natl. Acad Sci. USA $2005,102,4300$.

17. Boontheekul, T.: Kong, H.-T.; Hsiong, S. X.; Huang, Y.-C.; Mahadevan, L.; Vandenburgh, H.; Mooney, D. J. Faraday Discussions 2008, 139, 53.

18. Hampton, C. M.; Taylor, D. W.; Taylor, K. A.J. Mol Biol 2007. 368,92 .

19. Clark, E. A.; King, W. G.; Brugge, I. S.: Symons, M: Hynes, R. O. J. Cell Biol 1998, 142,573 . 